\title{
Technology and Knowledge Worker Productivity
}

\author{
Chandan Agarwala \\ Manager, Strategy \& Research \\ IGATE Global Solution, Unit 62, \\ Seepz, Andheri (East), Mumbai
}

\begin{abstract}
One of the fundamental assumption driving technology investment is more the merrier. The benefits achieved at task level for individuals are expected to eventually roll-up to organization-level productivity improvements. This paper explores the un-intended impacts of technology that stifles users' ability, to realize the full potential of organizational investment. While current generation of technologies has the ability to empower and engage employee's on-the-go, even in personal times, sometimes they threaten to imbalance personal life. Organizations need to exercise restraint to manage harmful impacts of multi-tasking and information overload caused by these technologies. The analysis is based on secondary research and empirical observations. These insights can help in product development and service offerings using newer technologies. Even, organizations and end-users can learn to frame appropriate roll-out plans and organization policies for technology adoption.
\end{abstract}

\section{General Terms}

Knowledge Worker, Productivity, Technology

\section{Keywords}

Human Augmentation, Technology RoI, Productivity Optimization

\section{INTRODUCTION}

Technology applications have mostly helped to reduce dependence on physical labor, resulting in improvement in the knowledge quotient of work. For example: Applications like desktop tools for personal productivity[1], leveraging internet, multi-channel communication, and mobile devices have widespread impact across all categories of work. Though these applications have existed in bits and pieces for more than a decade, now they have reached a threshold level, to impact the macro-level processes. They are helping to realize the vision of ubiquitous computing, empowering employees for anytime, anywhere contribution to organization goals. The dynamics of impact of newer generation of technologies on knowledge workers is studied in following sections:

- Literature Review section focuses on Labor and Automation, Knowledge Work and Information Workplace, Productivity Paradox, and Technology Cycles

- Discussion section focuses on Our Empirical Observation, Un-intended Consequences, Recommendations, and Limitations

\section{LITERATURE REVIEW}

\subsection{Labor and Automation}

With increasing usage of technology, the share of manual content is going down continuously (Figure 1) across all kinds of work. The general nature of work for an individual is getting more cognitive, requiring more soft skills like imagination, thinking and feeling. Along with cognitive thinking, the value of people management and owning responsibility to ensure the desired outcome has grown.

Technology can automate repetitive tasks to match a desired outcome. This has led to the huge reduction is manual labor in agriculture and manufacturing. Even manual work in semiknowledge work like Clerical positions has reduced significantly. But, the amorphous nature of knowledge work is more[2][1], resulting in has huge variations in process and expected output. Therefore, it is nearly impossible to replace human senses with tools and machines.

But the beauty is that, every reduction in manual labor has created new jobs involving cognitive skills, directly and indirectly[3]. Example: As manual tilling of land has been replaced with usage of tractors, farmers need to learn about the machine, its maintenance requirements, and ways to improve effectiveness. Also, they have got the time and resources, to get weather updates and crop advisory using smartphones.

\subsection{Knowledge Worker and Information Workplace}

Technologies used by knowledge workers can be broadly segregated into two categories:

- Contributing to their core job, like CAD for engineers, and High performance computing based applications for stock brokers[4]

- Supporting the core job, like ability to consult online experts on social media, and ability to get real-time alerts for people management while on-the-go

For this paper, we are focusing on the latter category of technology infrastructure that is mostly an enabler of the core job. Its impact on improving employee productivity and customer reach, has reached a threshold level, to mandate a macro-level scrutiny and policy formulation. Major categories of applications for improving operational productivity are [5]:

- internet and social media to socialize and form community in virtual world

- unified communications to use multiple channels for interaction

- mobile devices (smartphones and tablets) to increase productivity on-the-go 

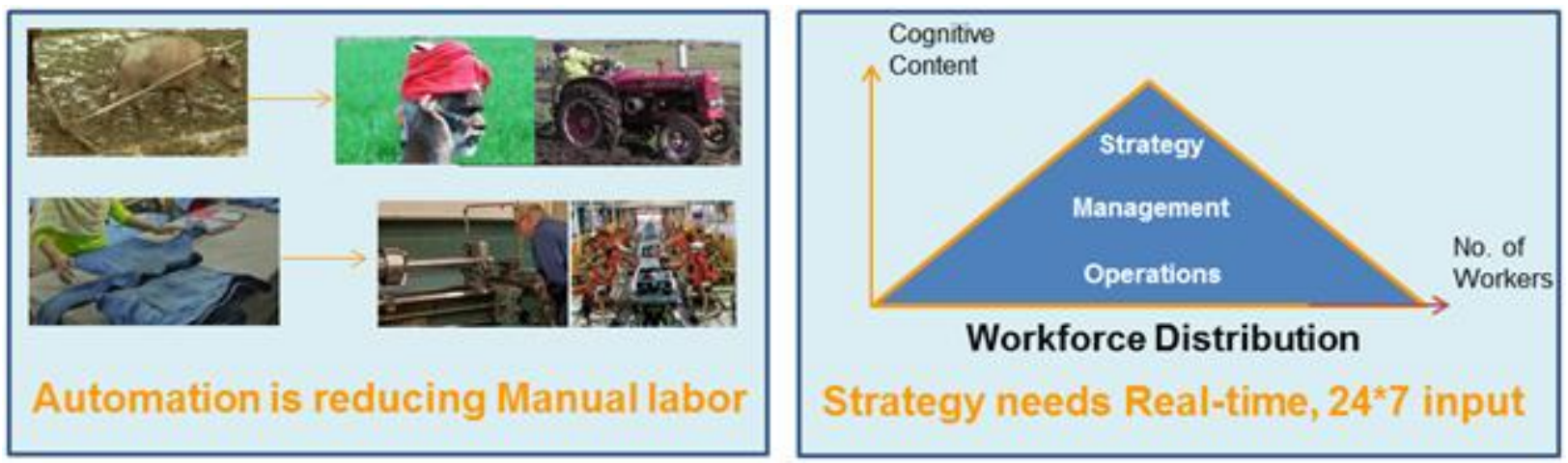

Fig 1: Growing Clout of Knowledge Worker

The core features of modern day information workplace are: collaboration, and communication (Figure 2). These technology applications are helping to work with team members, dispersed geographically and telecommute (work remotely).

\subsection{Productivity Paradox}

Most of the business case for technology utilization is based on the efficiency shown at the task level[6]. Example:

- Office tools help to store and retrieve structured and unstructure data.

- Multi-channel interaction is helping in real-time availability.

- Teleconferencing and Video-conferencing solutions are helping improve communication.

- Cloud Storage is helping to collaborate on document repositories.

The challenge has been to visualize the improvement at more abstract granularity[6]:

\subsubsection{Quality of output}

An outsourced, call center employee from Manila can respond to a U.S. customer using satellite communications and fourth generation networks. This will reduce the time lag in response. But, frequently the call center employee will not have knowledge of company procedures and local cultural nuances to resolve the customer query, satisfactorily[8]. So, even if, one aspect of the work is being done satisfactorily, the output may suffer in terms of customer satisfaction.

\subsubsection{Personal productivity}

All kinds of tools are making individuals more productive in their personal life and professional life. Sometimes, the unwanted impact can harm the prospects of an adequate output, or the potential productivity improvements, might not be realized to the complete extent[8].

\subsubsection{Team productivity}

As distributed co-creation is gathering momentum with individual spread across regions, based out of different time zones, team productivity is likely to be positively impacted due to the developments in information workplace and remote contribution/productivity[9]. It is contributing to sustenance effort by reducing the need for people to travel.

\subsubsection{Organization}

At organization level, the impact of technology becomes more abstract and qualitative. It is very difficult to ensure a direct correlation with revenue and margin, as a large number of factors work together to influence the output. Many times the qualitative impact is seen in terms of improvement in customer satisfaction and client retention. Sometimes, one business unit tries to keep the customer data restricted to meet regulatory compliance, while the other unit needs the same data for cross-selling[10].

\subsubsection{Country}

At country-level, GDP (Gross Domestic Product) and labor productivity are two primary parameters. Some studies have
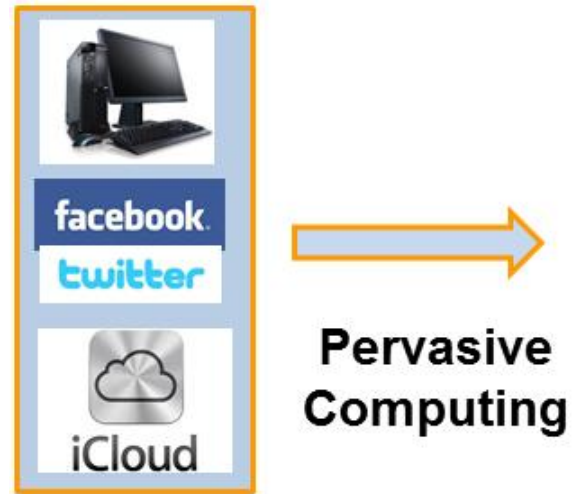
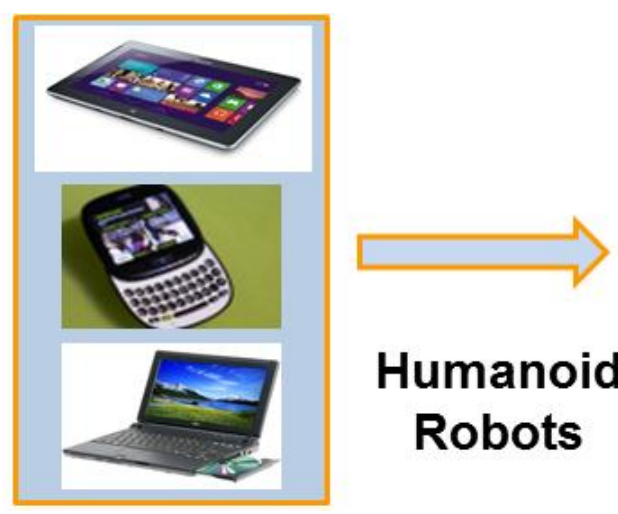
Humanoid Robots

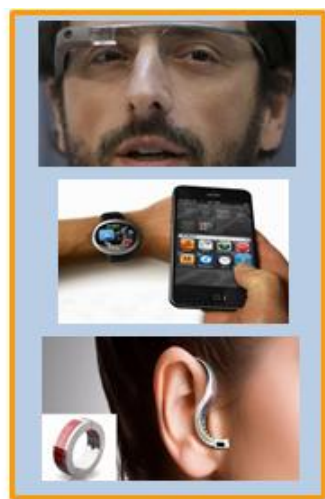

Fig 2: Able to Collaborate 24*7, On-the-Go Effectively 
shown that GDP and labor productivity has increased in the same time frame, as the emerging technologies have been adopted. But, it is difficult to justify such empirical observation, logically, considering the multiplicity of factors involved.

\subsection{Technology Cycles}

As the commercial applications of a technology develop in real-world, they need ecosystem of service providers, and proper infrastructure to ensure quality of service, at relatively affordable cost. Though use cases are hyped due to the novelty factor as soon as a technology comes out for pilot implementation, it moves along many rounds of commercial application, customer usage and feedback for product development[11].

For example: the ability of internet has grown with social media, and mobile devices. Vendor initiatives like social networking sites from Facebook and Twitter, and smartphones/tablets from Apple and Samsung has driven the commercial success. It is expected to grow more to realize the potential of video calling and virtual reality, as the higher network bandwidth from $4 \mathrm{G}$ networks will become a reality.

\section{DISCUSSION}

\subsection{Our Survey}

While most of our analysis is influence by our empirical observations and personal experience, we interacted with many individuals for formal and informal discussions. In spite of the popular resistance to acknowledge negative impacts of technology usage, few individuals were ready to share their views formally.

Table 1. Participants' Profile

Ranking different aspects of Work (1: High, 2 Medium, 3: Low)

\begin{tabular}{|l|c|c|c|c|c|c|c|}
\hline $\begin{array}{c}\text { Participant } \\
\text { Serial No. }\end{array}$ & $\mathbf{1}$ & $\mathbf{2}$ & $\mathbf{3}$ & $\mathbf{4}$ & $\mathbf{5}$ & $\mathbf{6}$ & $\mathbf{7}$ \\
\hline Cognitive & 2 & 1 & 2 & 1 & 1 & 1 & 1 \\
\hline Repetitive & 1 & 2 & 1 & 2 & 3 & 2 & 2 \\
\hline $\begin{array}{l}\text { People } \\
\text { Management }\end{array}$ & 3 & 3 & 3 & 3 & 2 & 3 & 3 \\
\hline
\end{tabular}

Most of the participants of the survey were from a Research department (Table 1). They had a higher amount of cognitive thinking, as part of their job role.

Table 2. Participants' Profile Primary mode of Team Interaction

\begin{tabular}{|c|c|c|c|c|c|c|c|}
\hline $\begin{array}{c}\text { Participant } \\
\text { Serial No. }\end{array}$ & $\mathbf{1}$ & $\mathbf{2}$ & $\mathbf{3}$ & $\mathbf{4}$ & $\mathbf{5}$ & $\mathbf{6}$ & $\mathbf{7}$ \\
\hline Face-to-face & Yes & Yes & & Yes & Yes & Yes & Yes \\
\hline $\begin{array}{c}\text { Meetings/ } \\
\text { Repositories }\end{array}$ & & & Yes & & & & \\
\hline $\begin{array}{c}\text { Mobile/ } \\
\text { Social Media }\end{array}$ & & & & & & & \\
\hline
\end{tabular}

Primary mode of team interaction was face-to-face (Table 2). This can be understood, considering that the non-verbal cues help in communicating the state of various emotion associated with a research process, while iterating a statement. For example: whether someone is suggesting as advice or, as instruction.
Table 3. Participants' Profile Managerial Role for Managing Real-time Escalations

\begin{tabular}{|c|c|c|c|c|c|c|c|}
\hline $\begin{array}{c}\text { Participant } \\
\text { Serial No. }\end{array}$ & $\mathbf{1}$ & $\mathbf{2}$ & $\mathbf{3}$ & $\mathbf{4}$ & $\mathbf{5}$ & $\mathbf{6}$ & $\mathbf{7}$ \\
\hline Never & & Yes & & & & & \\
\hline Occasionally & Yes & & Yes & Yes & Yes & Yes & Yes \\
\hline Frequently & & & & & & & \\
\hline
\end{tabular}

Participants did not require to manage real-time escalations, which require unscheduled interactions, and sometimes the urgency can mandate real-time responses (Table 3).

Table 4. Multi-channel Interaction for Real-time, 24*7 availability - Responses from Survey Participants

\begin{tabular}{|c|c|c|c|c|c|c|c|}
\hline $\begin{array}{l}\text { Participant } \\
\text { Serial No. }\end{array}$ & 1 & 2 & 3 & 4 & 5 & 6 & 7 \\
\hline $\begin{array}{l}\text { Improves } \\
\text { Productivity }\end{array}$ & & & & & & Yes & \\
\hline \multicolumn{8}{|l|}{ Nice to Have } \\
\hline $\begin{array}{c}\text { Sometime } \\
\text { creates } \\
\text { Hassles }\end{array}$ & Yes & Yes & Yes & & & & Yes \\
\hline $\begin{array}{l}\text { Does not } \\
\text { allow to } \\
\text { focus }\end{array}$ & & & & Yes & Yes & & \\
\hline
\end{tabular}

Only one among the seven participants, felt the real-time interactions enabled by multi-channel technologies is improving productivity. Most of them regarded it as contributing to productivity loss in some prevalent scenarios.

The survey has re-affirmed hassles for cognitive work, due to multi-channel interaction, requiring real-time, impromptu response.

\subsection{Unwanted Consequences}

Each genre of technology revolution has resulted in unwanted consequences (Figure 3), mapping to its unique characteristics:

- Mechanical action of frequent checking of e-mails and messages for updates is driving robotic behavior. This compulsive action is driven by an inherent urge to stay in touch with development, as they happen, without any urgency. Affected individuals are not able to neither relax adequately nor, enjoy vacation and leisure activities.

- Advent of consumer applications into enterprise domain, has resulted in compromise with organization security and privacy, while infringing on personal liberty and family life

- Bring-Your-Own-Devices (BYOD) has been creating peer pressure to adopt latest gizmos, and impacting team productivity as performance may vary across individuals depending on their taste or, preference for technologies

- Virtual teams formed with geographically-dispersed participants require different management style, and more commitment from participants

- Multi-channel interaction, enabled by unified communications and wireless media, contributed to unscheduled interruptions resulting in multi-tasking [12] that impacts productivity 


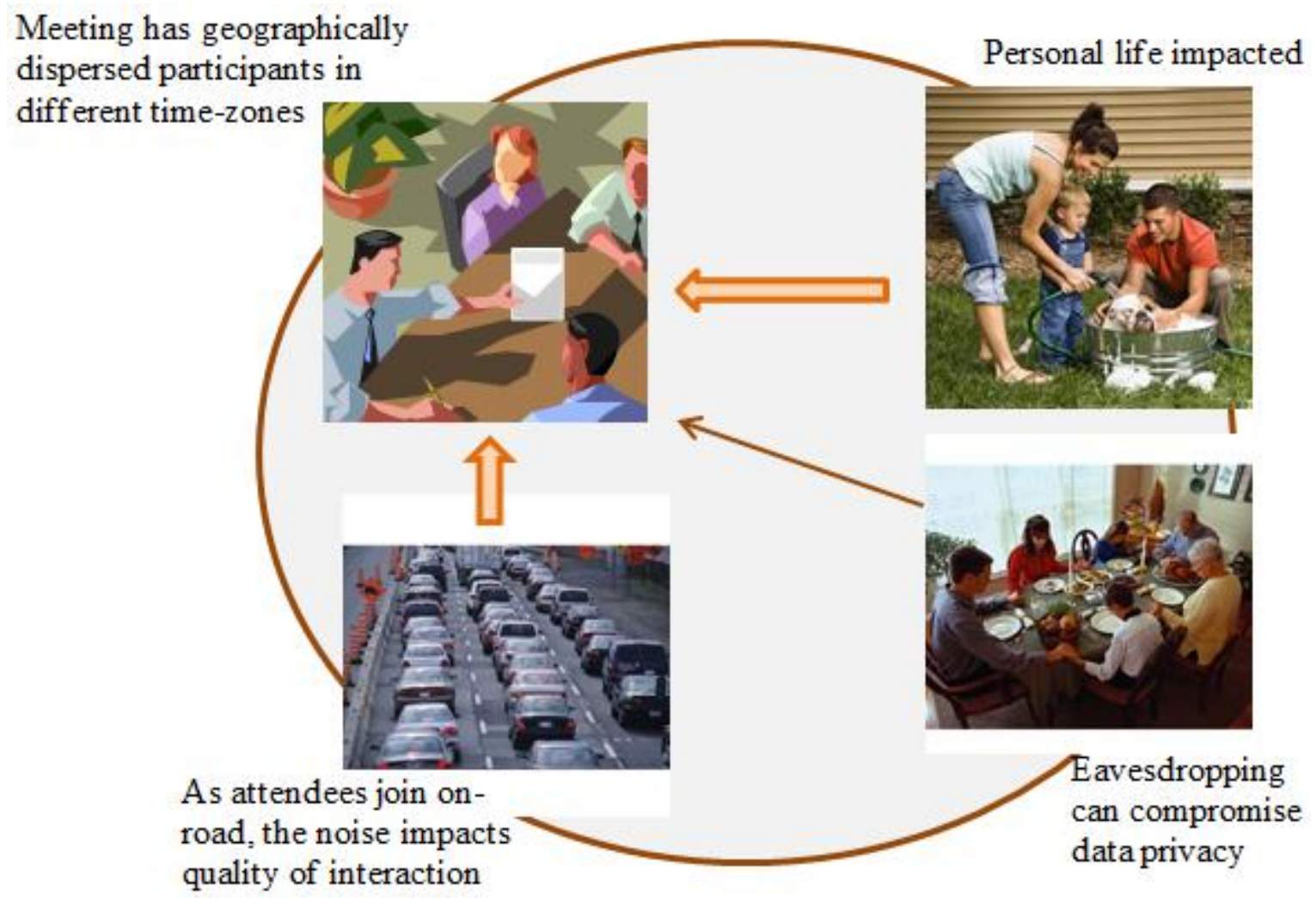

Fig 3: Unwanted Consequences of Technology can impact Productivity

- Information overload due to unbridled access to information on Internet, and large amount of unsolicited e-mails

- Packaged applications with in-built best practices impacts efficiency, as existing organizational practices require change management

\subsection{Recommendations}

\subsubsection{Schedule interruptions}

Need to minimize unscheduled interruptions, and convert them to scheduled breaks (multi-channel interaction): WorkLife balance has been improved, because individuals with responsibility are able to stay-in-touch with their work remotely and contribute in urgency. But the remote work and telecommute have combined to work in addition to regular office hours. This is taking toll on personal life. But, employees are feeling empowered and they want to take scheduled/voluntary breaks.

\subsubsection{Redefine business processes}

Enterprise business processes need to be redefined, to incorporate information workplace and contributions on-thego. Job roles are important. Acknowledge virtual teams cannot bond as strongly as exhibited due to physical colocation. Accordingly, set expectations from the technology deployment. Same logic applies to contribution on-the-go.

\subsubsection{Awareness programs}

Knowledge workers should be trained for managing communications on instant messenger and e-mail (multichannel interaction), and conducting virtual meetings[13]. Organizations should prepare for the long haul and expect negative productivity implications as users change the way they work: People need time to learn new tools, and get uses to replacing human interactions with electronic interactions. It is important to understand the social context of the individual too. Though it helps to stay connected, feel empowered and eases the jerk of returning to work, it can impact efficiency.

\subsubsection{Proportional technology paradigm}

Technology should be customized for local requirements, instead of implementing packaged applications in plug-andplay mode[14].

\subsubsection{Policies for culture and compliance}

There should be dedicated task force within organization to manage compliance aspects of various technologies. Example: Mobile devices have the risk of data security, Social media has the risk of informal communication, and Cloud storage has the risk of sending corporate data to un-disclosed locations.

\subsection{Limitations}

\subsubsection{Technology evolution}

As the novelty of virtual collaboration is wearing off, enterprises are recognizing the shortcomings of virtual collaboration and benefits of physical colocation. Also, the scope of virtual collaboration is going through change supported by developments in mobile devices and social media, wearable computing and virtual reality. The impacts will be known, by empirical validation.

\subsubsection{Economy scenario}

As job creation is not happening in current scenario, many of the employees' issues might have been suppressed in the guise of empowerment. While employers' are enjoying the 
productivity improvements, as job market recovers, the illeffects on personal life may get more prominence. For example: employees may resist peer pressure for complying B-Y-O-D norms, and prefer to opt-out, impacting team productivity.

\subsubsection{Offshore labor}

For manual labor, there are two possible scenarios: Automate at onsite (near customer locations, with high labor cost), and Leverage low-cost labor at offshore. The offshore output can be compared with onsite output. For knowledge work, the comparison of onsite output and offshore output is not straight forward. Onsite worker with the advantage of personal productivity tools and superior knowledge of local culture will be more equipped to use sensibility and cognitive power dynamically. Comparatively, offshore worker can be trusted with knowledge work for research and development, and document review and analysis that do not require external interface. The impact of technology on offshoring of knowledge work is undergoing a change, as not only the effectiveness of offshore labor has grown; the ability of onsite worker has also improved.

\subsubsection{Political pressure}

Usage of technology is expected to change the work profile, and require re-skilling of existing workforce. The workers experienced in old set-up will take time to grasp the changed infrastructure, and they will be at a disadvantage compared to workers with experience in new technology infrastructure. This burden of re-skilling is closely related to retrenchment policies and involuntary attrition. Political pressure is forcing organizations to take care of re-skilling of older employees, instead of evaluating their ability fairly. If this political activism grows, organizations will need to include the cost of reskilling and incentives to motivate existing employees in their technology roll-out budget.

\section{CONCLUSION}

Sometimes technology implementation may not be realizing the potential improvement in productivity, due to un-intended impacts. The task level efficiencies may harm productivity at more abstract level, like team productivity and organization culture. As the operational benefits of technology are proven, their usage is essential to organization survival. However, there is need to exercise restraint in rolling-out newer technology infrastructure and frame adequate support practices to take maximum advantage of potential productivity improvement. Additionally, factors like local culture and personal life, nature of job role with respect to cognitive thinking and people management, regulatory impact on the industry, etc. should be evaluated.

As economy recovers, employees may demand more flexibility in work environment to enjoy personal life. Also, the maturity in technology adoption may uncover new trends associated with the dynamic of human-machine interaction.

The increasing productivity offered in the form of executing responsibility due to on-the-go availability is likely to make on-site knowledge workers more secured, from the threat of being substituted with low-cost, offshore counterparts.

For practitioners, the findings offer useful insights to improve effectiveness of technology deployment.

\section{ACKNOWLEDGMENTS}

Our thanks to Dr. Prasad Ramanathan who inspired and guided towards development of the paper.

\section{REFERENCES}

[1] Edwards, Cory 2012. Supercharging Productivity through workforce innovation. Forbes in press

[2] Matson, Eric and Prusak, Laurence 2010. Boosting the productivity of knowledge workers. McKinsey Quarterly

[3] Brynjolfsson, Erik 2013. Charting technology's new directions. McKinsey Insights \& Publications

[4] Ashurst, C., \& Freer, A. 2011. Knowledge Work Productivity as part of 'Benefits-led IT' project, Newcastle University.

[5] Gartner. The Nexus of Forces: Social, Mobile, Cloud and Information. Retrieved 2014, from www.gartner.com

[6] Davenport, Thomas H. 2011. Rethinking knowledge work: A strategic approach. McKinsey Quarterly

[7] Ark, Bart van, Inklaar, Robert, McGuckin, Robert 2002. "Changing Gear" Productivity, ICT and Service Industries: Europe and United States. Groningen Growth and Development Center. University of Groningen

[8] Maclean, Dinah, 1997. Lagging Productivity Growth in the Service Sector: Mismeasurement, Mismanagement or Misinformation? Research Department. Bank of Canada

[9] Ramanathan, P., \& Agarwala, C.. Case Study: Innovation management using Social media and analytics. Retrieved 2014 from Dssresources.com.

[10] Agarwala, C. (2013). Convergence of IT and Business Return-on-Investment (RoI) Perspective. Leveraging IT for Competitive Advantage (pp. 12-16). Global Journal of Business Information System, Enriched Publications.

[11] Gartner. (n.d.). Interpreting Technology Hype. Retrieved 2014, from www.gartner.com

[12] Bannister, F., \& Remenyi, D. (2009). Multitasking: the Uncertain Impact of Technology on Knowledge Workers and Managers. Electronic Journal Information Systems Evaluation Volume 12 Issue 1.

[13] Karr-Wisniewski, P., \& Lu, Y. (2010). When more is too much: Operationalizing technology overload and exploring its impact on knowledge worker productivity. Computers in Human Behavior, 1061-1072.

[14] Kamga, O. (2013). A Case for the Proportional Technologies Paradigm. Leveraging IT for Competitive Advantage (pp. 229-232). New Delhi: Enriched Publications.

[15] Bartel, P. Ann, Ichniowski, Casey, Shaw, Kathryn L., 2005. How does IT really affect Productivity? Paper 11773, National Bureau of Economic Research.

[16] Gordon, Davis B., Affordances of Ubiquitous Computing and Productivity in Knowledge Work, University of Minnesota 